\title{
UMA ANÁLISE DAS PRÁTICAS DOCENTES DE PROFESSORES UNIVERSITÁRIOS DA ÁREA DE SAÚDE
}

\author{
Célia Alves Rozendo* \\ Lizete Diniz Ribas Casagrande** \\ Jacó Fernando Schneider*** \\ Luiz Carlos Pardini ****
}

ROZENDO, C.A.; CASAGRANDE, L.D.R.; SCHNEIDER, J.F.; PARDINI, J.C. Uma análise das práticas docentes de professores universitários da área de saúde. Rev.latino-am.enfermagem, Ribeirão Preto, v. 7, n. 2, p. 15-23, abril 1999.

O estudo busca caracterizar as práticas docentes - a nivel de planejamento, execução e avaliação de atividades e de ensino-aprendizagem - utilizadas por professores de alguns cursos da área de saúde, no Brasil: Odontologia, Medicina, Enfermagem, Farmácia, Psicologia, Nutrição, Serviço Social e Medicina Veterinária. A amostra foi constituída por 29 professores, inscritos em uma disciplina de Didática a nivel de Pós-Graduação, que responderam a um questionário composto por questões semi-abertas. As respostas obtidas apontam para uma prática de educação "bancária", segundo a denominação de Paulo Freire, caracterizada por ênfase na transmissão de informações, cargas horárias muito grandes, pouca integração das disciplinas e aulas expositivas.

UNITERMOS: práticas docentes, professor universitário, área de saúde

\section{I - INTRODUÇÃO}

Nas duas últimas décadas, as universidades brasileiras têm se empenhado em aumentar o nível de qualificação acadêmica de seus professores, no que diz respeito à titulação de mestres e doutores. Esse processo tende a ser muito mais enfatizado nos próximos oito anos, prazo determinado pela Lei 9394/96 - a nova Lei de Diretrizes e Bases da Educação Nacional - para que as instituições de ensino superior se adaptem à exigência de que pelo menos um terço do seu corpo docente, apresente titulação acadêmica de mestrado e doutorado.

Ora, os professores universitários, de modo geral, mesmo os possuidores desses títulos acadêmicos, pouca relevância têm dado à sua formação como professores, isto é, à sua preparação para a função de ensino. Vários autores, como ABREU \& MASETTO ${ }^{1}$; BORDENAVE \& PEREIRA ${ }^{3}$; GODOY ${ }^{11}$; GIL $^{10}$; SALDANHA $^{18}$; RONCA \& ESCOBAR $^{17}$ vem alertando para a lacuna existente na formação dos docentes do ensino superior: o professor se caracteriza como um especialista no seu campo de conhecimento; este é, inclusive, o critério para sua seleção e contratação; porém, não necessariamente este professor domina a área educacional e pedagógica, nem do ponto de vista mais amplo, mais filosófico, nem de um ponto de vista mais imediato, tecnológico ${ }^{1}$. O pressuposto desta situação é de que "basta conhecer bem o assunto, para ser um professor", como muitas vezes ouvimos na Universidade; subjacente a tal afirmação, está a suposição de que, para o ensino superior, o mais importante é o domínio dos conhecimentos referentes à sua área de atuação: a formação didática não seria tão necessária, porque os alunos universitários - por serem adultos, por se submeterem a rigorosa seleção, e por estarem motivados pela profissionalização ao final do curso - estariam, "a priori”, preparados para aprender sozinhos.

Este quadro, a nosso ver, vem se alterando

\footnotetext{
* Enfermeira. Mestre em Enfermagem Fundamental. Docente do Departamento de Enfermagem da Universidade Federal de Alagoas. Doutoranda do Programa Interunidades Doutorado em Enfermagem da Escola de Enfermagem Ribeirão Preto-USP

** Pedagoga. Doutora do Departamento de Psicologia e Educação da Faculdade de Filosofia Ciências e Letras de Ribeirão PretoUSP

*** Enfermeiro. Mestre em EnfermagemPsiquiátrica. Docente do Departamento de Enfermagem da Universidade Estadual do Oeste do Paraná. Doutorando do Programa Interunidades Doutorado em Enfermagem da Escola de Enfermagem de Ribeirão Preto-USP

**** Odontólogo. Professor Livre Docente do Departamento de Radiologia da Faculdade de Odontologia de Ribeirão Preto-USP
} 
significativamente, a partir da visão crítica do ensino superior, que se desenvolveu com as várias iniciativas de avaliação institucional; estas mostraram, freqüentemente, que os alunos, ao fazerem a apreciação de seus professores, ressaltam sua competência técnica e apontam sua falta de didática, o emprego excessivo, quase exclusivo, da preleção ou aula expositiva, com baixíssima participação dos alunos ${ }^{3}$. Nossa vivência, como docentes do ensino superior, tem demonstrado uma preocupação crescente com a lacuna na formação pedagógica, e uma disposição cada vez maior dos professores para superála, buscando cursos de aperfeiçoamento e especialização em Didática do Ensino Superior, ou inscrevendo-se, em grande número, nas disciplinas de Didática ou Metodologia do Ensino Superior, oferecidas nos programas de pós-graduação, a nível de mestrado e doutorado.

O presente trabalho se insere no âmbito de uma dessas disciplinas, a Didática do Ensino Superior, ministrada a pós-graduandos da área de saúde, no Campus da USP, em Ribeirão Preto. A premissa que nos guiou foi a de que existe "necessidade premente de uma atitude sistemática de investigação, crítica e documentação de nossa ação educativa, na busca de uma explicitação de nossos padrões educacionais" ${ }^{\prime 17}$. E que melhor ponto de partida para uma pesquisa sobre a formação pedagógica do professor universitário, que um levantamento sobre os procedimentos didáticos que ele já conhece e utiliza, sobre suas experiências prévias como o ensino superior?

BIREAUD $^{2}$, analisando a situação do ensino universitário na França, fala da entrada da reflexão pedagógica no ensino superior, mesmo que esta entrada se efetue, na maior parte das vezes, por uma porta secreta: a insatisfação de alunos e professores com a formação oferecida, e a cobrança da sociedade, quanto à solução de seus problemas imediatos. Porta secreta ou não, é preciso que os docentes universitários passem a refletir sobre seu trabalho e sua prática pedagógica, interrogandose sobre a validade desta ou daquela técnica, deste ou daquele modelo pedagógico, e em introduzirmos novas práticas de ensino, a partir desta interrogação ${ }^{2}$.

\section{II - CONCEITOS BÁSICOS}

A prática pedagógica é, ao nosso ver, a expressão da luta dos homens em busca de sua humanização e liberdade; é a expressão de sua luta cotidiana pela tomada de consciência de sua condição, numa realidade concreta, socialmente construída, e que necessita ser superada. E tal superação só pode ser obtida através do diálogo e da solidariedade, respondendo e respeitando a vocação ontológica do homem, de ser sujeito?

Neste sentido, acreditamos que a escola pode concretizar-se enquanto um instrumento de humanização e de conscientização dos homens. Esta escola, porém, teria que atender aos fundamentos da prática pedagógica orientada para a liberdade, teria que assumir e submeterse aos requisitos do processo educativo crítico, processo este voltado para a responsabilidade social e política.

Um processo educativo com tais características deve estar munido de práticas pedagógicas e didáticas que não se preocupem apenas com o conteúdo a ser "ensinado", com as técnicas de ensino e com a avaliação da aprendizagem, conceitos que freqüentemente giram em torno do binômio aprovação/reprovação.

A educação superior, que temos hoje é aquela que, de maneira geral, prioriza as práticas pedagógicas que pouco contribuem para o desenvolvimento de uma sociedade de sujeitos sociais construtores de sua própria história. Pelo contrário, a concepção predominante é a de uma educação para o ajustamento, a adaptação às normas e padrões de comportamento considerados "adequados", em que aos educandos é imposta uma condição de passividade e subordinação à autoridade do educador. É a visão denominada por Paulo Freire, de "educação bancária", porque nela, educar se torna um ato de depositar informações na mente dos educandos, os quais irão recebê-las sem questionamento. A essa concepção tradicional, o pedagogo brasileiro opõe a de "educação conscientizadora", ou "educação libertadora", baseada na relação horizontal entre educador e educando, e visando o desenvolvimento da consciência crítica sobre a realidade. É, pois necessário, dizer que, nesta mesma escola tradicional, há espaço para a transformação, porque nela existem homens, e porque nela são concretizadas ações realizadas por homens e a eles destinadas.

Tal transformação "é possível, a medida em que o homem, como ser pensante, sujeito e objeto, processo e produto do trabalho, é o agente social, material e intelectual capaz de analisar, compreender e contribuir para transformar a realidade, a partir das contradições geradas pelo trabalho que realiza, em conjunto com os outros homens" (p.19).

A universidade, enquanto uma instituição social inserida numa realidade concreta, experimenta a dialética do movimento social. Ao mesmo tempo em que determina, é determinada; a mesmo tempo em que transforma a realidade, também reproduz esta realidade. Compartilha as contradições da sociedade e produz suas próprias contradições.

Assim, as práticas pedagógicas, realizadas em seu interior, são reflexo da sociedade e nela se refletem, espelhando a complexidade da dinâmica social e da interação humana. Conhecer tais práticas e desvelá-las é fundamental para a tomada de consciência, e decisivo para que sejam efetuadas ações no sentido de sua superação. 
Com a finalidade, pois, de melhor visualizar a ação didático-pedagógica realizada em cursos da área de saúde de algumas Universidades brasileiras, este estudo objetiva caracterizar as práticas docentes ao nível de planejamento, execução e avaliação de atividades de ensino-aprendizagem, utilizadas por professores destes cursos.

\section{IV - TRAJETÓRIA METODOLÓGICA}

\subsection{Sujeitos do estudo}

O trabalho foi realizado a partir das informações fornecidas por 29 docentes de cursos de graduação da área de saúde de diversas universidades, matriculados em uma disciplina de Didática ao nível de pósgraduação.Os docentes estão distribuídos segundo o curso, como segue: 10 de Odontologia, 05 de Enfermagem, 05 de Medicina, 04 de Farmácia e Bioquímica, 02 de Psicologia, 01 de Serviço Social, 01 de Nutrição e 01 de Medicina Veterinária.

\subsection{Caracterização do estudo}

O presente estudo se caracteriza como um levantamento descritivo ${ }^{19}$, uma vez que reúne dados sobre a freqüência com que alguns docentes universitários - reunidos para uma disciplina de pós-graduação na área de saúde - utilizam determinados procedimentos didáticos. Segundo SELLTIZ et al. ${ }^{20}$, tais estudos, também denominados formuladores ou exploratórios, têm como principal acentuação, a descoberta de idéias ou intuições. Seu objetivo é a formulação de um problema para investigação mais exata ou para criação de hipóteses, ou aumentar o conhecimento do pesquisador acerca do fenômeno, esclarecimento de conceitos, ou apresentação de um recenceamento de problemas considerados urgentes por pessoas que trabalham em determinado campo das ciências sociais, sem usar experimentação.

No caso deste trabalho, a escolha do levantamento descritivo se justifica pela necessidade de obter informações sobre as ações docentes já conhecidas e praticadas pelos sujeitos do estudo, antes de iniciar um programa de formação pedagógica que pretendia intervir na sua realidade, proporcionado condições para uma tomada de consciência e uma transformação na situação de ensino. O levantamento realizado permitiria a observação e descrição - em termos de freqüência - dos procedimentos didáticos usados pelos docentes, servindo como base para o planejamento do programa de estudos da disciplina em questão.
O instrumento utilizado para coleta de dados foi um questionário - em anexo - contendo elementos para a identificação e caracterização dos participantes, assim como 21 questões descritivas das práticas docentes, sendo 9 fechadas, 11 mistas - com alternativas fechadas e a possibilidade de explicação ou inclusão de alternativas e 1 questão aberta.

Os questionários foram entregues aos participantes do estudo no início de uma aula regular da disciplina citada e recolhidos ao final, devidamente respondidos. É importante salientar que, antes da entrega dos questionários, os pesquisadores explicaram o objetivo do trabalho e solicitaram a colaboração dos participantes, esclarecendo também que suas respostas seriam analisadas e comparadas para posterior publicação; os participantes foram também esclarecidos quanto aos cuidados tomados para manter em sigilo a sua identidade.

\subsection{Análise dos dados}

Para a análise, inicialmente procedemos à reunião, ordenação e descrição estatística dos dados, posteriormente reunindo-se em 3 grandes temas ou categorias de análise: 1) práticas de planejamento, 2) práticas de implementação ou execução do plano, e 3) práticas de avaliação. A interpretação dos resultados foi subsidiada, especialmente, pelo referencial teórico de Paulo Freire, principalmente o conteúdo que versa sobre a dicotomia entre o que ele chama de educação "bancária" e educação "conscientizadora".

\section{V - ANÁLISE E INTERPRETAÇÃO DOS RESULTADOS}

Dos 29 docentes que fizeram parte da amostra, 13 (44,8\%) estão matriculados em cursos de mestrado, $16(55,2 \%)$ em cursos de doutorado, 20 (69\%) encontramse no grupo etário de 23 a 35 anos, e $19(65,5 \%)$ são do sexo feminino. A maioria (79\%) concluiu o curso de graduação há mais de 5 anos e relata não ter participado de qualquer curso de didática ou metodologia $(58,6 \%)$. Os demais docentes $(41,4 \%)$ cursaram estas disciplinas na graduação ou em habilitação para a licenciatura, sem preparação destinada especificamente ao ensino superior.

Um número significativo dos docentes participantes da investigação (22) trabalha em universidades públicas, federais ou estaduais, correspondendo a $75,9 \%$ do total; os demais exercem atividades de ensino em escolas superiores privadas. Mais da metade $(62,1 \%)$ atua no magistério superior há até 5 
anos e os demais (37,9\%) lecionam há mais de 5 anos. Quanto às disciplinas que ministram, 24 docentes afirmam lecionar disciplinas da área profissionalizante, e apenas 5 referem atuação na área básica.

Os dados acima apontam para uma conjuntura que deve ser motivo de preocupação por parte dos educadores e dos formuladores de políticas educacionais. Isto porque, como vimos anteriormente, a maior parte dos docentes, que participaram do estudo, tem menos de 35 anos, ou seja, é um grupo considerado jovem e tem, no máximo, 5 anos de atuação no magistério superior, sem preparação específica para tal atividade. Entendemos por preparação específica, a capacitação do profissional para assumir a complexa atividade da docência, incluindo a formação pedagógica.

Acreditamos que a realização de cursos de Didática não seja suficiente para tornar um professor apto ao exercício da docência, mas sem dúvida é um recurso importante para sua preparação. Neste sentido, vemos a Didática como um instrumento para uma prática pedagógica mais crítica e responsável.

Embora estes resultados não sejam suficientes para fazer afirmações generalizadas, nossa experiência, enquanto docentes de distintas universidades, inseridas em diferentes realidades, justifica tal preocupação.

Procuraremos analisar e interpretar os resultados numa perspectiva crítica, tentando estabelecer relações entre os resultados encontrados e a realidade concreta da educação nacional. Para tanto, reunimos os dados em 3 categorias analíticas, a saber: 1) práticas de planejamento, 2) práticas de execução do plano, e 3) práticas de avaliação da aprendizagem.

Em relação à primeira categoria de análise práticas de planejamento - destacaremos a responsabilidade pela programação, as características, os componentes e os objetivos do programa, o conteúdo e a carga horária. Quanto à realização do planejamento da disciplina ministrada, $14(48,3 \%)$ responderam que o planejamento é feito pelo conjunto dos professores que ministram a disciplina; $6(20,7 \%)$ disseram que o planejamento é realizado pelo professor responsável pela disciplina; $5(17,2 \%)$ afirmaram que o planejamento é feito por eles mesmos e $4(13,8 \%)$ referiram outros modos de elaboração do plano, como: participação do Diretor ou coordenador do curso, chefia de Departamento, etc.

De acordo com $19(65,5 \%)$ dos respondentes, o programa planejado tem a característica de ser variável e adaptável, dependendo do grupo de alunos e dos professores. Tais resultados sugerem a possibilidade de haver flexibilidade e liberdade para planejar, além de uma tendência para adaptar o programa de acordo com as necessidades e interesses do grupo de alunos.

Vemos que, embora o planejamento seja feito dentro da prática tradicional, parece haver oportunidade de inovação e um certo espaço de democratização, uma vez que o conjunto dos professores participa do processo de planejamento. Desnecessário dizer que isto não garante que o ensino se realize de forma inovadora, democrática e conscientizadora, mas pode ser um indicativo de que os docentes, enquanto seres sociais, sujeitos de sua própria prática e existência, poderão contribuir para $o$ estabelecimento de uma universidade que ajude a construir uma sociedade mais justa e democrática. É importante lembrar também que o processo educativo e a escola não estão desarticulados do movimento da própria sociedade. Implica em dizer que a escola brasileira em geral, e a universidade em particular, respondem à dinâmica do movimento da sociedade brasileira, a qual encontra-se em um momento de transição, abrindo-se a novos comportamentos e incorporados novos valores.

Os objetivos, conteúdo, metodologia, critérios de avaliação, recursos, cronograma e referências bibliográficas são os componentes do programa utilizados por $22(75,9 \%)$ dos participantes. Ao caracterizar os objetivos da disciplina que lecionam, os docentes em sua maioria, afirmam que eles são de caráter geral e específico $(58,6 \%)$, com ênfase no domínio cognitivo $(82,7 \%)$, apesar de também considerarem o domínio afetivo $(34,5)$ e o psicomotor $(34,5 \%)$. Dentre os respondentes, 5 $(17,2 \%)$ referem não ter conhecimento sobre os termos acima.

Consideramos que estes resultados são importantes e merecem uma reflexão. É provável que a ênfase no domínio cognitivo seja reflexo da dominação que a concepção tecnicista exerce sobre a sociedade em diversos âmbitos. O setor saúde é um bom exemplo disto. De forma geral, os processos de formação dos profissionais da área privilegiam os aspectos técnicos de sua atuação. Desta maneira, o conhecimento técnico e o científico configuram-se como elementos centrais do processo educativo, muitas vezes constituindo-se em seu fim, ao invés de ser visualizado como um de seus instrumentos. Este é um dos fatores que contribui para a desarticulação do planejamento, tanto no que diz respeito aos seus aspectos internos, quanto à sua dimensão externa, uma vez que "os objetivos em educação não dizem respeito apenas a um fragmento do real a testar, mas a uma compreensão da realidade humana, que transcende os limites provinciais. Daí que não há como limitar o que de si é ilimitado"4 (p.53).

A fragmentação de que falamos acima expressase também através da organização e seleção dos conteúdos, os quais, não raramente, são orientados pela abordagem tradicional da educação - "educação bancária", segundo denominação do pedagogo Paulo Freire - na qual verifica-se "a ausência de um tratamento mais orgânico da questão do conteúdo, especificando o ideário pedagógico, os pressupostos subjacentes às 
diferentes formas de seleção e organização de conteúdos"14 (p.68).

No presente trabalho, os dados relativos ao conteúdo são relevantes. Segundo 17 docentes $(58,6 \%)$ há integração entre a disciplina por eles lecionada e outras do currículo; 7 (24,1\%) não sabem ou não responderam, e $5(17,2 \%)$ afirmam não haver integração entre sua disciplina e outras lecionadas. É importante destacar que, ao analisarmos algumas respostas que abordam a forma pela qual se dá a integração interdisciplinar, parece-nos razoável afirmar que o conceito de integração é colocado com um certo equívoco.

Para alguns docentes, há integração porque a sua disciplina "envolve conhecimentos de outras especialidades", há "treinamento em áreas simultâneas e com conteúdos complementares", porque existem "fundamentos oriundos de disciplinas básicas", e ainda, pelas "iniciativas pessoais dos docentes". Podemos ver que a integração da qual falam alguns professores não expressa a integralidade do processo educativo ou a integração que nele deve existir, ambas necessárias ao seu fortalecimento e sustentação. A integração, na qual acreditamos, diz respeito não apenas ao caráter multidisciplinar ou interdisciplinar do processo educativo, mas, especialmente à sua prática dialógica $\mathrm{e}$ transformadora, capaz de assumir "um compromisso verdadeiro com a realidade, e com os homens concretos que nela e com ela estão"7 (p.21).

Para os docentes que afirmam não haver integração entre as disciplinas por eles lecionadas e outras disciplinas do curso $(17,2 \%)$, isto ocorre, segundo eles, pela "dificuldade de comunicação entre os professores", pela "falta de interesse, pelo medo de perder os feudos", e porque "não existe um espaço institucional neste sentido".

De um ponto de vista crítico, é preciso entender que a integração, no processo educativo, "supõe compreender uma forma explícita de ensinar a partir de sua contribuição para a conservação ou para a transformação da realidade, através de seu conteúdo implícito"5 (p.22). Ou seja, é necessário compreender e explicitar a relação teoria-prática numa realidade objetiva, cuja construção é feita por sujeitos concretos em sua existência cotidiana. Neste sentido, o planejamento de ensino deveria traduzir-se "pela ação pedagógica direcionada de forma a se integrar dialeticamente ao concreto do educando, buscando transformá-lo"13 (p.43).

Com relação à carga horária das duas disciplinas, 13 docentes $(44,8 \%)$ tem disciplina de até 100 horas semestrais, 08 docentes $(27,6 \%)$ de 100 a 200 horas, 02 docentes $(6,9 \%)$ com mais de 200 horas, e 06 (20,7\%) referiram não conhecerem a carga horária de suas disciplinas.

Muitas vezes, na tentativa de solucionar os problemas, são efetuadas ações tradicionais de pouca eficácia, como por exemplo o aumento da carga horária. No Brasil, os cursos da área de saúde costumam ter disciplinas cujas cargas horárias são muito elevadas, divididas entre teoria e prática. Freqüentemente, alunos e docentes dispendem longos períodos diários dependendo da disciplina, podem estender-se por todo o ano - numa única disciplina. Os resultados obtidos nem sempre são satisfatórios, e não raro, propõe-se aumento da carga horária para sanar as dificuldades.

Neste estudo, verificamos que 15 docentes participantes acreditam que a carga horária das disciplinas que lecionam é adequada, 07 docentes $(24,1 \%)$ consideram inadequada e que necessitariam de mais horas para o ensino tanto da prática quanto da teoria, 05 docentes $(17,2 \%)$ referem não ter avaliado ainda esta questão, e 02 docentes $(6,9 \%)$ não responderam à questão. Ao nosso ver, isto também é reflexo de uma prática educativa, na qual verifica-se "a supremacia da dimensão técnico-instrumental em detrimento da abordagem epistemiológica" ${ }^{16}$ (p.83). E tal supremacia não está circunscrita apenas às práticas de planejamento, mas também está presente nas práticas de implementação nossa segunda categoria de análise - e nas práticas de avaliação - terceira categoria de análise - como veremos a seguir.

Quanto às práticas de implementação, abordamos os métodos de ensino e os recursos didáticos mais utilizados. Com relação aos métodos de ensino, 25 $(86,2 \%)$ dos docentes afirmam fazer uso da aula expositiva como método de ensino utilizado com mais freqüência, seguida por discussão de casos (48,3\%), aula prática de laboratório $(41,4 \%)$, aula prática de clínica $(34,5 \%)$, seminário $(27,6 \%)$ debate com toda a classe $(31,0 \%)$, trabalho em grupo $(17,2 \%)$ e aula prática de campo $(13,8 \%)$.

Esses resultados podem ser facilmente compreendidos se considerarmos as características do ensino fundamentado na abordagem tradicional, em que a "correspondente metodologia se baseia mais freqüentemente na aula expositiva e nas demonstrações do professor à classe" ${ }^{\prime 15}$ (p.15). Nesta metodologia, o conteúdo é trazido pelo professor, inteiramente delimitado, restando ao aluno escutá-lo passivamente. O processo ensino-aprendizagem é centrado no professor, e a reprodução, pelos alunos, dos conteúdos "ensinados", é o resultado esperado, indicando que houve "aprendizagem".

Os recursos didáticos de maior utilização, referidos pelos professores, foram o quadro-negro $(69,0 \%)$, seguido por retroprojetor e projetor de slides $(62,0 \%)$, situações reais/atendimento clínico $(48,3 \%)$ vídeo e tv $(27,6 \%)$ manequins $(20,7 \%)$ e filmes $(13,8 \%)$. $\mathrm{Na}$ educação tradicional ou educação bancária, o 
importante é a transmissão dos conteúdos pelo professor, o qual é depositado na cabeça dos educandos, a priori desprovidos de qualquer conhecimento.

Neste sentido, recursos didáticos que favoreçam a transmissão dos conteúdos e, de certa forma, ajudem a manter a relação professor-aluno verticalizada, são melhor aceitos e considerados mais "apropriados". Desnecessário dizer que estes recursos didáticos, assim como os métodos de ensino acima referidos, podem e devem ser utilizados em qualquer abordagem de ensino, desde que sejam visualizados como instrumentos, formas de mediação de uma relação professor-aluno mais igualitária.

Por fim, trataremos agora de uma questão que é sempre polêmica e delicada: a avaliação da aprendizagem. Destacaremos, aqui, os instrumentos utilizados, os momentos de avaliação e os critérios para aprovação. Dentre os instrumentos de avaliação citados, destaca-se a prova escrita, adotada por $23(79,3 \%)$ dos professores participantes da pesquisa. Os outros instrumentos, mais freqüentemente utilizados, são a observação do desempenho do aluno em aula $(51,7 \%)$, o trabalho escrito $(31,0 \%)$, o seminário $(31,0 \%)$ a prova prática $(20,7 \%)$ e a prova oral $(13,8 \%)$.

A maioria dos docentes $(72,5 \%)$ costuma fazer uma avaliação final de cada unidade ou ao final da disciplina. Os critérios utilizados para a aprovação dizem respeito à freqüência do aluno na sala de aula e à obtenção de uma nota final, que é a média resultante de outras aferições - variável para cada universidade. É interessante notar que vários participantes do estudo confundiram critérios de aprovação com critérios de avaliação.

No nosso entendimento, tanto os instrumentos de avaliação, quanto os momentos em que ela é feita, assim como os critérios para a aprovação, estão coerentes com a abordagem tradicional. Nela, "a avaliação é realizada predominantemente visando a exatidão da reprodução do conteúdo comunicado em sala de aula"15 (p.17)

Então, o que significa exatamente avaliar? Para $\operatorname{HADJI}^{12}$ (p.27), “Como toda e qualquer questão de sentido, a questão do sentido do termo arrisca-se mesmo a nunca ter uma resposta acabada. (...) se está sempre a avaliar, e se avaliar significa interpretar, nunca se chega a conseguir dizer em que é que consiste a avaliação, a qual nunca se poderá limitar, obviamente, a uma definição exacta".

No entanto, procura-se quantificar, através de notas e freqüência, o desempenho dos alunos, cuja avaliação se dá de acordo com a capacidade de reproduzir com exatidão o que foi "ensinado". Neste tipo de prática educacional, não há espaço para o desenvolvimento da capacidade de criar, inovar e pensar criticamente, inerente ao sujeito e necessária ao processo de transformação da sociedade.
"Mas, qualquer que seja o valor adoptado, não posso avaliar senão quando adoptar um valor, quer dizer, quando constituir uma 'idéia' ou um conjunto de 'idéias' como referente, em nome do qual se torna possível apreciar a realidade",12 (p.29).

\section{VI - CONSIDERAÇÕES FINAIS}

Começaremos nossas reflexões finais, que não são conclusivas, por dizer que acreditamos na transformação e na capacidade dos homens de construir sua história. Dito isso, reiteramos nossa conviç̧ão de que a escola em geral, e a universidade em particular, enquanto expressão da criação humana, possuem potencial e instrumentos capazes de contribuir para o desenvolvimento da sociedade em que estão inseridas. No Brasil, as diretrizes do processo de formação de nível básico e médio, sofrem determinação do que é concebido por órgãos localizados no âmbito central.

Segundo DANTAS ${ }^{6}$ (p.15), o "gigantismo e a burocratização desses órgãos, e a sua legião de técnicos encarregados de projetar, quantificar, fiscalizar o processo educativo, retiram da escola o seu poder de decisão, a sua autonomia de decidir os seus fins e sua forma de fazer a educação". Isto tem gerado uma lógica em que há supervalorização dos procedimentos, dos meios e das técnicas, em detrimento do fim da educação, que é a conscientização do educando sobre sua condição de ser humano e de ser sujeito.

Embora tal lógica também incida sobre a universidade, não podemos deixar de reconhecer que seu grau de autonomia é maior do que o da escola em geral. Os professores e coordenadores de cursos, como constamos, têm liberdade para definir conteúdos, estratégias, processo de avaliação, etc. ou seja, têm um certo controle sobre o processo de ensino-aprendizagem. O reconhecimento desta faceta da universidade é importante para o seu desvelamento, assim como para a sua transformação. O conhecimento acerca de suas práticas discentes e docentes é necessário ao processo contínuo de busca de soluções para seus problemas e dificuldades no âmbito pedagógico. Por fim, entender os determinantes e as implicações políticas é decisivo, não só para compreender a dinâmica do processo de mudança mas, especialmente, para fazer as mudanças.

Como vimos ao longo do trabalho, as práticas pedagógicas dos professores universitários refletem a ambigüidade e as contradições de sua profissão e da própria universidade. Além disso, estas práticas pedagógicas revelam que nossa prática educacional continua enraizada na concepção bancária da educação. No entanto, revelam também um certo desejo - ainda que silencioso - de ver, nelas refletida, a consciência crítica e 
criadora da educação, cujo fim é "permitir ao homem chegar a ser sujeito, construir-se como pessoa, transformar o mundo e estabelecer com os outros relações de reciprocidade, fazer a cultura e a história ..." ${ }^{8}(\mathrm{p} .42)$.

\section{AN ANALYSIS OF THE TEACHING PRACTICES OF FACULTIES IN THE HEALTH AREA}

The study aims to describe teaching practices - in planning, execution and evaluation of the teaching-learning process - used by faculty of some courses in the health field in Brazil: Odontology, Medicine, Nursing, Pharmacy, Psychology, Nutrition, Social Work and Veterinary Medicine. The sample was made up by 29 faculties enrolled in a didactic subject course at graduate programs. They answered a questionnaire with semi-open questions. The answers obtained point to a "banking" education practice, according to Paulo Freire. This kind of education is characterized by: 1) emphasis on the transmission of information; 2) many hours of education; 3) little integration between courses and 4) lecture classes.

KEY WORDS: teaching practices, faculty, health area

\section{UN ANALISIS DE LAS PRÁCTICAS DOCENTES DE PROFESORES UNIVERSITARIOS DEL ÁREA DE LA SALUD}

El estudio busca caracterizar las prácticas docentes a nivel de la planeación, ejucución y evaluación de actividades de enseñanza-aprendizaje, utilizadas por los profesores de algunos cursos del área de la salud en Brasil: Odontología, Medicina, Enfermería, Farmacia, Psicología, Serviço Social, Nutrición y Medicina Veterinaria. La muestra fue constituida por 29 profesores, inscritos en una disciplina de didáctica a nivel de postgraduación, que respondieron a un cuestionario compuesto por preguntas semi abiertas. Las respuestas obtenidas apuntan a una práctica de educación "bancaria", según la denominación de Paulo Freire, caracterizado por el énfasis en la transmisión de informaciones, cargas horarias muy grandes, poca integración de las disciplinas y clases magistrales.

TÉRMINOS CLAVES: prácticas docentes, profesor universitario, area de la salud

\section{ANEXO}

\section{PROTOCOLO DE PESQUISA}

Prezado aluno apreciaríamos que respondesse as questões formuladas. Suas respostas sinceras servirão de subsídios para os professores. Solicitamos que você responda ao questionário, reportando-se à sua prática como docente.

Nome: Idade: Sexo:

Curso Superior na área de: Ano de Formatura:

Títulos Universitários: Mestrado: ( ) Cursando ( ) Defendido no ano de:

Doutorado: ( )

Aluno Especial: ( )

Local de trabalho com atividade docente no Ensino Superior:

Tempo: anos. Disciplina(s) que leciona:

01) Freqüentou curso de Didática? ( ) Não ( ) Sim Há quanto tempo? anos.

02) Como é realizado o planejamento da disciplina que você leciona?

a) Pelo professor que é o responsável pela disciplina

b) Pelo conjunto de docentes que ministram a disciplina

c) Por você sozinho

d) De outro modo. Qual? Cite-o

03) Esse programa planejado é:

a) Fixo para todos os docentes

b) Fixo a toda as turmas (subdivisão dos alunos) c) Variável para cada docente

d) Variável a cada turma (subdivisão dos alunos)

e) Variável e adaptado pelo docente para cada turma (subdivisão dos alunos)

f) Fixo, o mesmo conteúdo quando oferecida a disciplina

g) Variável e modificado quando oferecida a disciplina

h) Outro. Qual? Cite-o

04) Esse programa contém os seguintes componentes:

a) Objetivos, conteúdo, metodologia, critérios de avaliação

b) Objetivos, conteúdo, metodologia, critérios de avaliação, recursos, cronograma, referências bibliográfica

c) Ementa, conteúdo programático, metodologia, critérios de avaliação

d) Outros itens. Qual? Cite o componente

05) Se o programa de sua disciplina contém objetivos, eles são:

a) Gerais (ou educacionais)

b) Específicos (ou instrucionais)

c) ambos (gerais e específicos)

d) Não sei (não conheço esses termos)

e) Outros. Qual? Cite-os

06) Os objetivos de sua disciplina são de domínio (você pode responder mais de uma alternativa):

a) Cognitivo

b) Afetivo

c) Psicomotor

d) Não sei (não conheço esses termos) 
07) O conteúdo programático da disciplina: (você pode assinalar mais de uma alternativa)

a) É fixado na secretaria da disciplina

b) É fixado na Seção de alunos

c) É distribuído para os alunos

d) Não é distribuído para os alunos

e) É distribuído para os alunos e só é explicado

08) Assinale os critérios utilizados na seleção do conteúdo programático de sua disciplina:

a) Exigido para o exercício da atividade profissional

b) Atualidade

c) Significativo para o aluno (aplicabilidade)

d) Interesse da profissão

e) Adequado ao nível de compreensão do aluno

f) Conteúdo mais comum na bibliografia da área

g) Conteúdo mais comum em outras Universidades

h) Outros. Qual? Cite-o

09) O conteúdo de sua disciplina é integrado com de outras disciplinas?

( ) Não sei

( ) Sim. Como?

( ) Não. Por que?

10) Sua disciplina é pré-requisito para outra disciplina?

( ) $\mathrm{Sim}$

( ) Não

( ) Não sei

11) Ou, exige pré-requisito de outra disciplina?

( ) $\mathrm{Sim}$

( ) Não

( ) Não sei

11a) em caso afirmativo: você conhece o conteúdo programático da disciplina que é exigido como pré-requisito da sua?

( ) $\mathrm{Sim}$

( ) Não

( ) Em parte

12) Sua disciplina é oferecida:

( ) Semestralmente

( ) Anualmente

13) Há quanto tempo você ministra a(s) disciplina(s):

14) A carga horária de sua disciplina é de horas. ( ) Não sei

15) Essa carga horária em sua opinião é:

a) Adequada

b) Inadequada c) Não fiz ainda essa avaliação

d) Não sei

16) Assinale os métodos de ensino que utiliza com maior freqüência:
a) Aula expositiva
b) Seminário
c) Aulas práticas e laboratório
d) Aulas práticas de campo
e) Aulas práticas de clínica
f) Trabalho em grupo
g) Discussão de casos
h) Debate com a classe toda
i) Estudo dirigido
j) Instrução individualizada
k) Outro. Qual? Cite-o

17) Assinale os recursos didáticos que você utiliza com maior freqüência:
a) Projetor de Slides
b) Retro-Projetor
c) Filmes
d) Vídeo e TV
e) Fotos, Gravuras, Cartazes
f) Álbum Seriado
g) Quadro Negro
h) Manequins
i) Situações Reais
j) Outros. Qual? Cite-os

18) Assinale os instrumentos de avaliação da aprendizagem que você utiliza com maior freqüência:

a) Prova Escrita

b) Prova Prática

c) Prova Oral

d) Trabalho Escrito

e) Seminário

f) Observação do desempenho do aluno em aula ou em estágio

g) Outro. Qual? Cite-o

19) Quando você faz a avaliação do aprendizado?

a) No início da disciplina

b) Ao final da unidade ou tema

c) Ao final da disciplina

d) Outro. Qual? Cite-o

20) Descreva o(s) critério(s) de aprovação de sua disciplina:

\section{REFERÊNCIAS BIBLIOGRÁFICAS}

01. ABREU, M.C.; MASETTO, M.T. O professor universitário em aula: prática e princípios teóricos. 11. ed. São Paulo: MG Ed. Associados, 1997.

02. BIREAUD, A. Os métodos pedagógicos no ensino superior. Trad. de Irene Lima Mendes. Porto: Porto Editora, 1995.

03. BORDENAVE, J.D.; PEREIRA, A.M. Estratégias de ensino-aprendizagem. Petrópolis: Vozes, 1977.
04. CAStAnho, M.E. de L. e M. Os objetivos da educação. In: VEIGA, I.P. de A. (coord.). Repensando a didática. 11.ed. Campinas: Papirus, 1996. p.53-64.

05. DAMIS, D.T. Didática: suas relações, seus pensamentos. In: VEIGA I.P. de A. (coord.). Repensando a didática. 11.ed. Campinas: Papirus, 1996. p.13-40.

06. DANTAS, L. Capacitação de educadores e política educacional: contribuição à discussão teórica. Educação em Questão, v.5, n.2, p.9-18, jul/ dez.1993. 
07. FREIRE, P. Educação e mudança. 15.ed. Rio de Janeiro: Paz e Terra, 1989.

08. Conscientización. Buenos Aires: Ediciones Busquedas, 1974.

09. Educação como prática da liberdade. 5.ed. Rio de Janeiro: Paz e Terra, 1975.

10. GIL, A.C. Metodologia do ensino superior. São Paulo: Atlas, 1994.

11. GODOY, A.S. Didática para o ensino superior. São Paulo: Iglu, 1988.

12. HADJI, C. A avaliação, regras do jogo: das intenções aos instrumentos. Portugal: Porto Editora, 1994.

13. LOPES, A.O. Planejamento do ensino numa perspectiva crítica da educação. In: VEIGA, I.P. de A. (coord.). Repensando a didática. 11.ed. Campinas: Papirus, 1996. p.41-52.

14. MARTINS, P.L. O Conteúdos escolares: a quem compete a seleção e organização?. In: VEIGA, I.P. de A. (coord.). Repensando a didática. 11.ed. Campinas: Papirus, 1996. p.65-82.
15. MIZUKAMI, M da G.N. Ensino: as abordagens do processo. São Paulo: EPU, 1986.

16. RAYS, O.A. A questão da metodologia do ensino na didática escolar. In: VEIGA, I. P. de A. (coord.). Repensando a didática. 11.ed. Campinas: Papirus, 1996. p.83-95.

17. RONCA, A.C.; ESCOBAR, U.F. Técnicas pedagógicas: domesticação ou desafio à participação?. 3.ed. Petrópolis: Vozes, 1984.

18. SALDANHA, L.E. (org.) Planejamento e organização do ensino: um manual programado para o treinamento do professor universitário. 6 . ed. Porto Alegre: Globo, 1985.

19. SEAMAN, C.C.; VERHONICK, P.G. Research methods for undergraduate students in nursing. USA: Apleton-Century Croft, 1982.

20. SELLTIZ, C. et al. Métodos de pesquisa nas relações sociais. Trad. de Dante Moreira Leite. São Paulo: EDUSP, 1971. 